\title{
Is clear cell sarcoma a malignant form of psammomatous melanotic schwannoma?
}

\author{
Case report
}

\author{
Ahmet Şengöz, M.D., Erol TaşdemiroĞlu, M.D., and Halit Togay, M.D. \\ Department of Neurosurgery, Istanbul Education Hospital, Istanbul, Turkey
}

\begin{abstract}
$\checkmark$ The authors present a case of clear cell sarcoma (CCS) in which the tumor originated in the S-1 nerve root and had been previously diagnosed as psammomatous melanotic schwannoma (PMS). This is the third case of a spinal nerve root origin for CCS reported in the English-language literature. The similar histogenesis of CCS and malignant melanoma supports the hypothesis that biological agents or immunotherapy are potentially important areas of investigation.

The patient underwent S1-3 laminectomy and gross-total resection of the mass lesion. The border of the resection was extended $1 \mathrm{~cm}$ distal to the tumor margin. The postoperative period was uneventful. The new histopathological diagnosis was CCS (malignant melanoma of soft tissue). Despite total resection, the patient returned with disseminated disease at the 18-month follow-up visit. His follow-up magnetic resonance image of the lumbar spine revealed sacral L5-S3 involvement of the vertebral bodies along with disseminated cauda equina seeding.

A CCS originating from peripheral nerves is quite rare. The histopathological and immunohistochemical appearance of CCSs resembles those of PMSs. Surgery should be the first choice of treatment.
\end{abstract}

\section{KEY WORDS • clear cell sarcoma • psammomatous melanotic schwannoma • Carney complex • histopathological study}

$\mathrm{E}$ NZINGER $^{5}$ first described the CCS of tendons and aponeuroses after reviewing 21 cases from the files of the Armed Forces Institute of Pathology. In 1983, the term "clear cell sarcoma of tendons and aponeuroses" was changed to "malignant melanoma of the soft parts" when melanin was demonstrated in $72 \%$ of 92 tumors. ${ }^{15}$ We present a case of CCS that originated from the S-1 nerve root and had been previously diagnosed as PMS. This is the third reported case in the English-language literature of CCS originating in a spinal nerve root.

\section{Case Report}

History. This 41-year-old Caucasian man presented with right leg pain and numbness and was admitted to Incirli Hospital in Istanbul on October 5, 2001. Fourteen months previously, he had undergone partial resection of a right S-1 nerve root tumor. The histopathological study of the surgical material yielded a diagnosis of PMS. After the histopathological diagnosis was established, the possibility of Carney complex was ruled out by an extensive workup. ${ }^{1}$

Examination. During the second hospital admission, results of the patient's physical examination and vital signs

\footnotetext{
Abbreviations used in this paper: CCS = clear cell sarcoma; $\mathrm{MR}=$ magnetic resonance; PMS = psammomatous melanotic schwannoma.
}

were within normal limits. His neurological examination yielded normal results, except for right lower-extremity paresthesia in the $\mathrm{S}-1$ distribution. A $\mathrm{T}_{1}$-weighted axial MR image (Fig. 1A) of the lumbar spine demonstrated a mass lesion with $3 \times 3 \times 2-\mathrm{cm}$ dimensions originating from the S-1 nerve root. After gadolinium injection, the tumor enhanced diffusely on $\mathrm{T}_{1}$-weighted sagittal (Fig. 1B) and axial (Fig. 1C) images. On a $\mathrm{T}_{2}$-weighted axial MR image of the lumbar spine, the mass lesion demonstrated heterogeneous hyper- and hypodense areas caused by melanin pigment in the tumor tissue (Fig. 2).

Operation and Postoperative Course. The patient underwent S-3 laminectomy and gross-total resection of the mass lesion. The distal border of the tumor resection was extended $1 \mathrm{~cm}$ distal to the tumor margin. The postoperative period was uneventful. The new histopathological diagnosis was CCS (malignant melanoma of soft tissue; Fig. 3 ). The patient was in stable condition without recurrence or metastasis at the 6-month postoperative follow-up visit.

\section{Discussion}

We present a case of CCS that originated from the S-1 nerve root. This is the third reported case of this type of lesion originating from the peripheral nerve sheath. Parker et al. ${ }^{11}$ described the first spinal CCS case in 1980. In their case the patient was an 18-year-old Caucasian woman, and her physical examination also revealed many brown skin macules resembling café-au-lait spots, and a $3-\mathrm{cm}-$ 

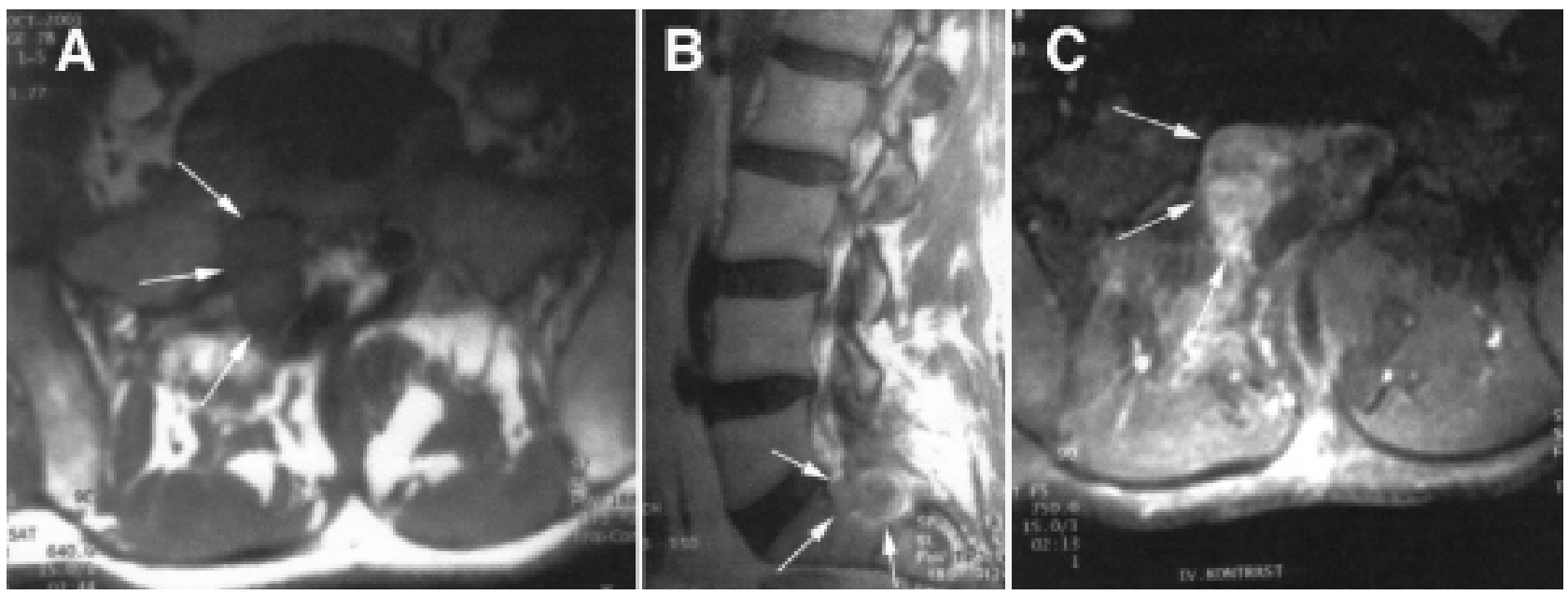

FIG. 1. Axial $\mathrm{T}_{1}$-weighted MR image of lumbar spine (A) revealing a mass lesion (arrows) with $3 \times 3 \times 2-\mathrm{cm}$ dimensions, which originated from the S-1 nerve root. After gadolinium injection, both $\mathrm{T}_{1}$-weighted sagittal (B) and axial (C) images demonstrated diffuse enhancement.

diameter fibroadenoma in the left breast. The majority of the features of Carney complex suggest a similarity with this unique case of spinal CCS and with the other pigmented nerve sheath tumors (for example, PMS). In the second case, which was reported by Schnarkowski et al., ${ }^{13}$ the tumor originated from the median nerve sheath. In our case, the previous histopathological diagnosis was PMS. During the second operation, however, the histopathological diagnosis of the same lesion was changed to CCS.

Malignant peripheral nerve sheath tumors are typically deep-seated and affect large and medium nerves. Major sites include the brachial and lumbar plexuses and sciatic and spinal nerves. The most common site of origin is the sciatic nerve.

The PMSs may affect the spinal and cranial nerves, including vestibular and trigeminal nerves. Approximately one half of the patients with PMS had Carney complex, which is a syndrome with dominant inheritance that is characterized by bilateral primary pigmented nodular adrenocortical hyperplasia; multiple lentigines (particularly of the head and neck) and blue nevi; cutaneous and cardiac

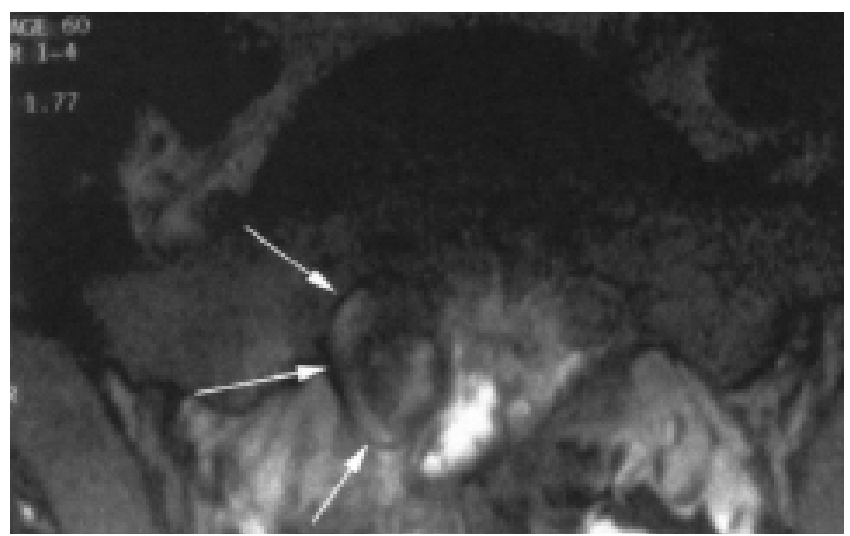

FIG. 2. Axial $\mathrm{T}_{2}$-weighted MR image of the lumbar spine demonstrating the mass lesion (arrows) with its heterogeneous hyperand hypodense areas due to melanin pigment in the tumor tissue. myxomata; large cell calcifying Sertoli cell tumors of the testis; myxoid fibroadenomas of the breast; pituitary tumors; and PMSs. ${ }^{1}$ The neurosurgeon must be aware of the possible malignancy of PMS. It was previously thought that melanotic schwannomas were benign lesions, but metastases can arise from sporadic melanotic schwannomas as well as from the PMS associated with Carney complex. ${ }^{16}$

Peripheral nerve tumors are among the most diverse of all soft-tissue tumors, both in terms of clinical behavior and histological features. In the past, because there were no precise pathological definitions of the principal types of peripheral nerve tumors, physicians were prevented from offering consistent advice about appropriate treatment. Recent studies focusing on the ultrastructural and immunohistochemical characteristics of the principal tumor types have largely resolved this problem. Subsequent clinicopathological studies, among other data, contradict the once commonly held notion that any peripheral tumor containing mitotic figures is necessarily malignant.

Unfortunately, there is currently no reliable histopathological indicator for malignancy. Although some aggressive and metastasizing melanotic schwannomas have demonstrated marked pleomorphism, high mitotic activity, and a malignant peripheral nerve sheath tumor-like fascicular growth pattern, most large cell, epithelioid, melanotic schwannomas with high mitotic activity have followed a benign course. ${ }^{8}$ Conversely, some of the melanotic schwannomas that manifest malignant behavior are histologically indistinguishable from those that are benign. Because the immunohistochemical staining with miscellaneous markers and the special features under light microscopic examination of both CCS and PMS overlapped (Table 1), the CCS could be the malignant form of PMS, both in sporadic cases and in those of the Carney complex.

A rare sarcoma displaying melanocytic differentiation, CCS of soft tissues accounts for only 0.8 to $1 \%$ of all malignant lesions of the musculoskeletal system. ${ }^{3,6}$ The exact histogenesis of this tumor is obscure, but the presence of intracellular melanin in two thirds of cases supports an 


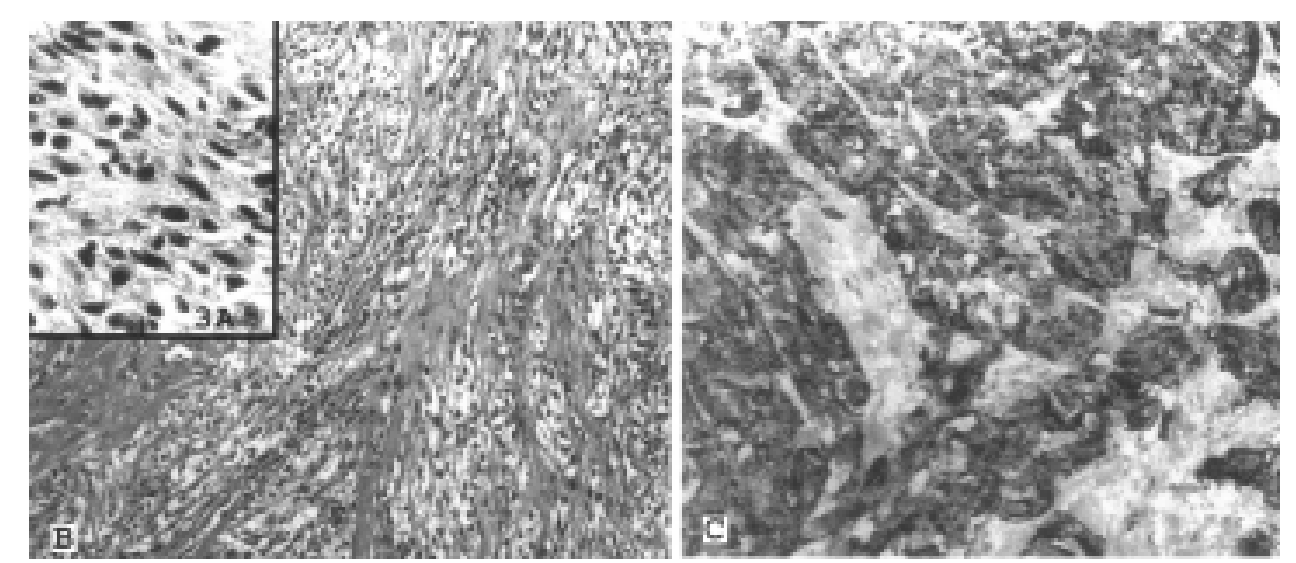

Fig. 3. Photomicrographs of typical CCS showing uniform plump spindle cells with clear-to-pale cytoplasm separated into nests by fibrous septae. The tumor cells are spindly or polygonal and show pale and clear-to-pale cytoplasm, and ovoid and vesicular nuclei. The tumor cells show diffuse and strong positivity after staining with the HMB-45 antibody. $\mathrm{H} \& \mathrm{E}$, original magnification $\times 310$ (A) and $\times 150$ (B); immunostaining with HMB-45, original magnification $\times 310(\mathrm{C})$.

origin from migrated neural crest cells that have the capacity of producing melanin. This neoplasm presents most frequently in adolescents or young adults, with a slight female predominance, as a slow-growing, often painful nodule, most commonly located at the level of the extremities, head, trunk (abdominal wall, back, and neck), hip, shoulder, buttock, duodenum, peripheral nerve sheath of a spinal nerve root, and bone. . $^{4,5,9,11-13,17}$

These lesions are mostly well defined, and because they lack perilesional edema, bone invasion, satellite nodules, or intratumoral necrosis, they can be erroneously interpreted as benign lesions on MR images. More than one half of these lesions with melanocytic differentiation have a slightly increased signal intensity compared with muscle on $\mathrm{T}_{1}$-weighted MR images. Substances that exhibit rapid $T_{1}$ relaxation and therefore a high-intensity signal on $T_{1}-$ weighted images include fat, methemoglobin, and melanin. Melanin causes paramagnetic relaxation enhancement of surrounding tissue, with shortening of $T_{1}$ and $T_{2}$ values, resulting in higher intensity on $\mathrm{T}_{1}$-weighted and lower intensity on $\mathrm{T}_{2}$-weighted MR images. ${ }^{7}$ However, only the

\section{TABLE 1}

Similarities detected between immunohistochemical staining and light microscopy appearance of CCSs and PMSs

\begin{tabular}{lll}
\hline \hline \multicolumn{1}{c}{ Feature } & CCS & PMS \\
\hline on immunohistochemical staining & & \\
S-100 protein & $+/-$ & + \\
melanocyte marker HMB-45 & $+/-$ & + \\
vimentin & + & $+/-$ \\
$\quad$ cytokeratin & $+/-$ & - \\
on light microscopy & & \\
polygonal to spindle cells & + & + \\
$\quad$ separated by delicate fibrous septae & & \\
$\begin{array}{l}\text { clear or slightly basophilic cytoplasm } \\
\text { ovoid \& vesicular nucleus }\end{array}$ & + & $+/ *$ \\
eosinophilic nucleolus & + & + \\
\hline
\end{tabular}

* Acidophilic cytoplasm. Abbreviations: $+=$ presence of immunohistochemical and light microscobic findings; $-=$ their absence; $+/-=$ both possibilities. lesions containing more than $23 \%$ melanin demonstrate increased signal intensity on $\mathrm{T}_{1}$-weighted images. ${ }^{2} \mathrm{In}$ our case, the mass lesion demonstrated heterogeneous hyperand hypodense areas on both $\mathrm{T}_{1}$ - and $\mathrm{T}_{2}$-weighted $\mathrm{MR}$ images (Figs. 1 and 2); this appearance was due to the melanin content of the tumor. After gadolinium injection, the tumor enhanced diffusely on $\mathrm{T}_{1}$-weighted images (Fig. $1 \mathrm{~B}$ and $\mathrm{C})$.

The imaging-based differential diagnosis should include other lesions characterized by their high signal intensity on $\mathrm{T}_{1}$-weighted images. Lipomatous lesions such as lipoma, well-differentiated liposarcoma, and lipoblastoma generally have much higher signal intensities on $\mathrm{T}_{1}$ weighted images, and are easily differentiated using fat saturation techniques or short-tau inversion-recovery images. Alveolar soft-tissue sarcoma has a high signal intensity on $\mathrm{T}_{1}$ - and $\mathrm{T}_{2}$-weighted MR images. High signal intensity on $\mathrm{T}_{1}$-weighted images is also seen in melanocytic schwannoma.

Although CCS often has a benign appearance on MR images, it behaves as a relentless, highly malignant softtissue sarcoma with a tendency for local recurrence and metastatic spread. A usually rapid, fatal progression can occur, but a protracted clinical course with metastases appearing after a quiescent phase of many years is not uncommon. ${ }^{3}$ Tumor size, the presence of necrosis, and perhaps DNA index are the only factors identified as having some influence on survival. Local control is very important and is best obtained by complete excision with or without adjuvant radiotherapy. In Enzinger's ${ }^{5}$ series, the local recurrence rate was $84 \%$, probably reflecting a conservative surgical approach. In subsequent studies ${ }^{9,10}$ rates between 14 and $26 \%$ have been reported. Regional lymph node metastases develop in approximately one third of patients sometime during the follow-up period. Distant metastases to the lungs are even more common. After the occurrence of distant metastasis, the prognosis is dismal. ${ }^{3}$ Whether radiation therapy acts as an independent parameter of survival remains questionable, and chemotherapy has no appreciable beneficial effect. In contrast, a remarkable response to interferon- $\alpha-2 b$ has been reported. ${ }^{14}$ 
The only features found to predict outcome were the presence of necrosis and tumor size, with tumors greater than $5 \mathrm{~cm}$ in diameter having a worse prognosis. ${ }^{15}$ Patients undergoing a wide excision or amputation had a mean survival duration of 10 years, whereas patients with marginal or intralesional margins had a mean survival duration of 6 years. ${ }^{5}$

The similar histogenesis of CCS and malignant melanoma support the suggestion that biological agents or immunotherapy may be rewarding areas of investigation. ${ }^{6}$

\section{Conclusions}

Clear cell sarcomas originating from peripheral nerves are quite rare. The histopathological and immunohistochemical appearance of the CCS resembles that of the PMS. Surgery should be the first choice for treatment.

\section{References}

1. Carney AJ: Psammomatous melanotic schwannoma. A distinctive, heritable tumor with special assocations, including cardiac myxsoma and the Cushing syndrome. Am J Surg Pathol 14: 206-222, 1990

2. De Beuckeleer LH, De Schepper AM, Vandevenne JE, et al: MR imaging of clear cell sarcoma (malignant melanoma of the soft parts): a multicenter correlative MRI-pathology study of 21 cases and literature review. Skeletal Radiol 29:187-195, 2000

3. Deenik W, Mooi WJ, Rutgers EJ, et al: Clear cell sarcoma (malignant melanoma) of soft parts: a clinicopathologic study of 30 cases. Cancer 86:969-975, 1999

4. Ekfors O, Kujari H, Isomaki M: Clear cell sarcoma of the tendons and aponeuroses (malignant melanoma of the soft parts) in the duedonum: the first visceral case. Histopathology 22: 255-259, 1993

5. Enzinger FM: Clear cell sarcoma of tendons and aponeuroses: an analysis of 21 cases. Cancer 18:1163-1174, 1965

6. Finley JW, Hanypsiak B, McGrath B, et al: Clear cell sarcoma: the Roswell Park experience. J Drug Oncol 77:16-20, 2001

7. Gandolfo N, Martinoli C, Cafiero F, et al: Malignant melanoma of soft tissues (clear cell sarcoma) of the foot. Is MRI able to
A. Şengöz, E. Taşdemiroğlu, and H. Togay

perform a specific diagnosis? Report of one case and review of the radiological literature. Anticancer Res 20:3993-3998, 2000

8. Kindblom LG, Meis-Kindblom JM, Nelson JS, et al: Melanotic schwannoma. A study of 42 cases. Lab Invest 72:7A, 1995 (Abstract)

9. Lucas DR, Nascimento AG, Sim FH: Clear cell sarcoma of soft tissues. Mayo Clinic experience with 35 cases. Am J Surg Pathol 16:1197-1204, 1992

10. Montgomery EA, Meis JM, Ramos AG, et al: Clear cell sarcoma of tendons and aponeuroses: a clinicopathologic study of 58 cases with analysis of prognostic factors. Int J Surg Pathol 1: 89-100, 1993

11. Parker JB, Marcus PB, Martin JH: Spinal melanotic clear-cell sarcoma: a light and electron microscopic study. Cancer 46: 718-724, 1980

12. Sara AS, Evans HL, Benjamin RS: Malignant melanoma of soft parts (clear cell sarcoma): a study of 17 cases with emphasis on prognostic factors. Cancer 65:367-374, 1990

13. Schnarkowski P, Peterfy CG, Johnston JO, et al: Clear cell sarcoma mimicking peripheral nerve sheath tumor. Skeletal Radiol 25:197-200, 1996

14. Steger GG, Wrba F, Mader R, et al: Complete remission of metastasised clear cell sarcoma of tendons and aponeuroses. Eur J Cancer 27:254-256, 1991

15. Swanson PE, Wick MR: Clear cell sarcoma. An immunohistochemical analysis of six cases and comparison with other epithelioid neoplasms of soft tissue. Arch Pathol Lab Med 113:55-60, 1989

16. Watson JC, Stratakis CA, Bryant-Greenwood PK, et al: Neurosurgical implications of Carney complex. J Neurosurg 92:413-418, 2000

17. Yokohama R, Mukai K, Hirota T, et al: Primary malignant melanoma (clear cell sarcoma) of bone: report of a case arising in the ulna. Cancer 77:2471-2475, 1996

Manuscript received July 30, 2006.

Accepted in final form November 16, 2006.

Address reprint requests to: Ahmet Şengöz, M.D., Ihlas Marmara Evleri 2. Etap, C:9 D:3 Beylikduzu, 34520-TR, Turkey. email: ahmetsengoz@yahoo.com. 